\title{
A Negative Ion Mass Spectrometry Approach to Identify Cross-Linked Peptides Utilizing Characteristic Disulfide Fragmentations
}

\author{
Antonio N. Calabrese, Nikki J. Good, Tianfang Wang, Jingjia He, John H. Bowie, \\ Tara L. Pukala \\ School of Chemistry and Physics, The University of Adelaide, Adelaide, SA, 5005, Australia
}

\begin{abstract}
Chemical cross-linking combined with mass spectrometry (MS) is an analytical tool used to elucidate the topologies of proteins and protein complexes. However, identification of the low abundance cross-linked peptides and modification sites amongst a large quantity of proteolytic fragments remains challenging. In this work, we present a strategy to identify cross-linked peptides by negative ion MS for the first time. This approach is based around the facile cleavages of disulfide bonds in the negative mode, and allows identification of cross-linked products based on their characteristic fragmentations. $\mathrm{MS}^{3}$ analysis of the cross-linked peptides allows for their sequencing and identification, with residue specific location of cross-linking sites. We demonstrate the applicability of the commercially available cystine based cross-linking reagent dithiobis(succinimidyl) propionate (DSP) and identify cross-linked peptides from ubiquitin. In each instance, the characteristic fragmentation behavior of the cross-linked species is described. The data presented here indicate that this negative ion approach may be a useful tool to characterize the structures of proteins and protein complexes, and provides the basis for the development of high throughput negative ion MS chemical cross-linking strategies.
\end{abstract}

Key words: Negative ion mass spectrometry, Chemical cross-linking, Disulfide fragmentations, Protein structure determination

\section{Introduction}

$\mathrm{D}$ etailed characterization of the tertiary and quaternary structures of proteins and protein complexes is vital for understanding protein function and the regulation of intricate cellular processes. The choice and applicability of different analytical techniques to achieve this structural characterization is dependent on the system being studied, with many systems not amenable to conventional high-resolution

Electronic supplementary material The online version of this article (doi:10.1007/s13361-012-0407-x) contains supplementary material, which is available to authorized users.

Correspondence to: Tara L. Pukala; e-mail: tara.pukala@adelaide.edu.au techniques like nuclear magnetic resonance spectroscopy and X-ray crystallography. This is particularly the case for low abundance or dynamic protein assemblies, where transient structures and interactions are present.

Chemical cross-linking coupled with mass spectrometry (MS) is a low-resolution approach that can be used for protein structure analysis, and has recently been reviewed [1-5]. Briefly, a reactive cross-linker is added to form covalent bonds with the protein, trapping its conformational state. Following chemical cross-linking, proteolytic cleavage of the cross-linked protein and subsequent mass spectrometric analysis is typically conducted. The cross-linking reaction may yield one of several products, namely intermolecular, intramolecular, and dead-end cross-linked 
peptides. The sites of the cross-linking modifications may be used to generate constraints, allowing the approximation of the structure of a protein or protein complex; dead-end adducts yield information about solvent accessibility, intramolecular cross-links may give information about local structural elements (i.e., secondary and tertiary structure) whilst intermolecular cross-links give distance information that may be used in modeling applications and to define binding interfaces [6]. It is a particularly useful technique for studying transient and weak protein interactions, as they are covalently trapped, and offers significant advantages over the conventional techniques previously mentioned, due to its speed, sensitivity and adaptability.

Despite the relative straightforwardness of the crosslinking methodology, broad application of this approach has been limited primarily by analytical challenges. For example, detection and identification of the cross-linked peptides, which provide structural information, amongst the plethora of other proteolytic fragments, remains difficult due to their relatively low concentrations. Furthermore, peptide identification and location of the specific amino acids within the protein that contain the cross-linker modification is hindered by often complex MS fragmentation behavior [3]. Consequently, the development of new methodologies for the identification of these cross-linked peptides is of fundamental importance.

Several approaches to aid the identification of crosslinked peptides from complex mixtures have been developed. These include incorporating an affinity tag into the linker for peptide purification [7-14], as well as various isotope labeling strategies [15-19]. These methods, however, often yield complex, difficult to analyze MS/MS data, as the intermolecular cross-links consist of two peptides covalently joined, and product ions from both peptides are present in the spectrum [20]. Several cleavable cross-linkers have been developed to assist in the identification process, including collision induced dissociation (CID) cleavable reagents [12, 20-25], as well as others that are chemically cleaved prior to MS analysis $[11,16]$. CID cleavable crosslinkers may afford products corresponding to a reporter ion of known $m / z$ [12, 22], or cleavage of the cross-linker at a defined position, giving fragment ions corresponding to each of the two linked peptides [21, 23, 24, 26, 27]. In certain designs, both are incorporated $[12,28]$. Identification of the peptide fragments is achieved by application of $\mathrm{MS}^{\mathrm{n}}$ analysis.

Labile disulfides have been previously integrated into the design of chemical cross-linking reagents as they are easily reduced chemically prior to MS analysis. This approach, however, is unreliable as it is dependent on observing signals of cross-linked products both before and after reduction, which may lead to ambiguities in cross-link assignment. These reagents have also shown limited use as positive ion mode CID-cleavable cross-linking reagents as linker cleavages compete with backbone fragmentation, complicating the spectra, and have been shown to be charge-state dependent $[25,29]$. However, in the negative ion mode, disulfide bonds within peptides undergo facile cleavage upon collisional activation [30-34]. The fragment anions produced are readily identifiable, and sequence information can be obtained by CID of the resultant product ions [35].

Here we investigate for the first time the applicability of a negative ion MS approach to identify protein chemical cross-links. In particular, the fragmentation pathways of disulfide containing linkers at relatively low activation energies, conditions often used to fragment labile crosslinker bonds whilst maintaining the integrity of the peptide backbone, are studied. We show that cross-linked peptides fragment in a reliable and characteristic way, allowing direct identification of cross-linking adducts by negative ion MS with residue specific resolution from a single experiment. This study, therefore, demonstrates the applicability of this ionization mode as a potential analytical tool to investigate the structural properties of proteins and protein complexes.

\section{Experimental}

\section{Materials}

Unless otherwise specified, chemicals were purchased from Sigma Aldrich (St. Louis, MO, USA) and used as received. Dithiobis(succinimidyl propionate) (DSP) was purchased from Thermo Scientific (Rockford, IL, USA). Sequencing grade modified trypsin was purchased from Promega (Madison, WI, USA). Ac-IR7 peptide (Ac-IEAEKGR, $843.94 \mathrm{~g} \cdot \mathrm{mol}^{-1}$ ) was synthesized in-house using standard Fmoc solid phase methods on 2-chlorotrityl chloride resin (GL Biochem, Shanghai, China) and purified by HPLC to greater than $95 \%$ purity.

\section{Cross-Linking of Ac-IR7}

Ac-IR7 $(0.3 \mathrm{mg}, 355 \mu \mathrm{mol})$ was dissolved in DMSO $(275 \mu \mathrm{L})$ and $14 \mu \mathrm{L}$ of a $1 \mathrm{mM}$ DSP solution was added (1 eq.) along with diisopropylethylamine $(0.2 \mu \mathrm{L}, 1$ eq. $)$. The mixture was incubated at room temperature for $5 \mathrm{~h}$ with periodic mixing, before being concentrated to dryness using a SpeedVac concentrator. The residue was dissolved in water and desalted by ZipTip (Millipore, Bedford, MA, USA) before MS analysis. These non-physiological experimental conditions were employed to attain high yields of the cross-linked products for analysis, allowing for characterization of the fragmentation pathways with relative ease from this model system.

\section{Cross-Linking of Ubiquitin}

Bovine ubiquitin was dissolved in phosphate buffered saline at a concentration of $200 \mu \mathrm{M}(40 \mu \mathrm{L})$ and a 10-fold molar excess of DSP was added from a $10 \mathrm{mM}$ solution in DMSO (4 $\mu \mathrm{L})$. The reaction mixture was incubated at room temperature for $1 \mathrm{~h}$ and digested overnight with trypsin 
$4 \%$ (wt/wt). The cross-linked peptides were then lyophilized and desalted by ZipTip before MS analysis.

\section{MS Analysis}

Nano-electrospray mass spectra were acquired using a Micromass QTOF2 orthogonal acceleration time-of-flight mass spectrometer. Samples were introduced into the spectrometer using platinum-coated borosilicate capillaries prepared in-house. Conditions were as follows: capillary voltage $1.4 \mathrm{kV}$, source temperature $80{ }^{\circ} \mathrm{C}$, and cone voltage 30-50 V. Ar collision gas energies of approximately 15$30 \mathrm{eV}$ were used for 'low energy' CID, while 'high energy' CID utilized collision gas energies of 30-50 eV. Fragments created by capillary-skimmer dissociation were generated by applying cone voltages of typically $70 \mathrm{~V}$ and were then mass-selected for further MS/MS analysis (described in text as 'pseudo $\mathrm{MS}^{3}$ experiments'). Spectra were deconvoluted using the maximum entropy algorithm in MassLynx software (Waters, Manchester, UK).

\section{Quantum Mechanical Modeling}

A model system $\left[\mathrm{H}_{3} \mathrm{CNHCO}\left(\mathrm{CH}_{2}\right)_{2} \mathrm{~S}-\mathrm{SCH}_{2}{ }^{-}\right.$ $\mathrm{CHCONHCH}_{3}$ ] was used to investigate the reaction mechanisms. Calculations were carried out at the CAM-B3LYP/ $6-311++\mathrm{g}(\mathrm{d}, \mathrm{p})$ level of theory [36-38], using the Gaussian 09 suite of programs [39]. Minima connected by a given transition structure were confirmed by intrinsic reaction coordinate (IRC) calculations [40-42]. Stationary points were characterized as either minima (no imaginary frequencies) or transition states (one imaginary frequency) by calculation of frequencies using analytical gradient procedures. All calculations were performed using supercomputing facilities from eResearch SA (the South Australian Partnership for Advanced Computing, The University of Adelaide) and the Australian Partnership for Advanced Computing (Australian National University, Canberra).

\section{Results and Discussion}

\section{Cross-Linker Rationale}

In any cross-linking strategy, it is vital to first understand the characteristic, diagnostic fragmentation pathways of the cross-linked products for structure identification. This study aimed to determine the applicability of cystine-like disulfidecontaining chemical cross-linking reagents for use with negative ion MS for analysis of protein conformation. Historically, negative ion MS has had limited application for the study of complex systems as the MS/MS data of peptides are often dominated by side chain-induced fragmentations [31, 35], whereas spectra in the positive ion mode generally show characteristic backbone cleavages well suited to peptide sequencing. However, equally important and complementary information can be obtained from both ionization modes, and many examples exist whereby negative ion MS allows for mapping of disulfide bonds in proteins with greater ease [30, 33, 34].

Negative ion MS cleavages of underivatized peptides as well as those of intra- and intermolecular cystine disulfides have been well studied. CID of symmetrical intermolecular disulfide bonded peptides in the negative ion mode results in facile fragmentation, affording a maximum of four product ions, corresponding to cleavages at or adjacent to the disulfide bond (Scheme 1) [32, 33]. These cleavages are effected by either an enolate anion or by an anion situated directly adjacent to the disulfide and are amongst the most energetically favorable of all the negative ion peptide cleavages studied, with low transition state barriers [33], and therefore occur in preference to backbone fragmentation at low collision energies.

Product anions A and C in Scheme 1 are formed as a result of charge transfer via an ion-neutral complex whilst<smiles>[R]NC(CSSC1CC1)C([R])=O</smiles><smiles>[R]C(=O)C(=C)N([2H])C</smiles><smiles>[R]C(=O)C(CS[S-])NP</smiles><smiles></smiles><smiles>[R]NC(C=S)C([R])=O</smiles>

Scheme 1. Characteristic fragmentations of the naturally occurring cystine disulfide [31]. Masses of the ions are indicated relative to fragment anion $\mathrm{A}$ (denoted by the arbitrary mass, M). It should be noted that the enolate ions drawn throughout this paper have an additional contributing mesomeric resonance structure (not drawn). Structures of product anions $B$ and $D$ can be rationalized directly from the proposed reaction mechanisms, whilst anions $A$ and $C$ are formed by charge transfer via an ion-neutral complex [33] 
the anion sites in product ions $\mathrm{B}$ and $\mathrm{D}$ can be rationalized directly from the proposed reaction mechanisms (see reference [33]).

The basis of our negative ion cleavable cross-linking approach is a disulfide-containing cross-linking reagent, which is expected to effect analogous cleavages to those shown in Scheme 1, but where both the initiating enolate and $-{ }^{-} \mathrm{CH}-\mathrm{S}-\mathrm{S}-$ anion sites are situated on the linker. To differentiate the cleavages of the cross-linker from those of the natural cystine disulfide, ions from the cross-linked adducts analogous to those shown in Scheme 1 are denoted A'-D'. Exploiting these facile cleavages in this approach is ideal as breakage of the cross-link can be initiated by up to four anions (two on each side of the disulfide), yielding a maximum of four ions for each peptide involved in the cross-link. These processes should occur readily and are easily recognizable by the characteristic fragment ions they produce (even when all four possible products are not observed), and the exact location of the crosslinking site can be identified by standard negative ion $\mathrm{MS}^{3}$ sequencing once individual peptides are released, making data analysis reliable and fast.

The amine-reactive, commercially available dithiobis (succinimidyl propionate) (DSP) (Supplementary Figure 1) is a disulfide-containing cross-linking reagent with the structural features required to effect cleavage of the types shown in Scheme 1, with the enolate and $-{ }^{-} \mathrm{CH}-\mathrm{S}-\mathrm{S}-$ initiating anions situated on the cross-linker. This reagent has been chosen as the basis of our study as it also has wellestablished cross-linking characteristics. Additionally, MS/ MS analyses of this reagent in the positive mode have been utilized to identify peptide cross-links [25] and it is our aim to directly demonstrate the advantages of a negative ion approach using the same cross-linker.

\section{MS Fragmentation of Model Cross-Linked Peptides}

To experimentally ascertain the low-energy CID fragmentation patterns of intermolecular cross-links introduced by
DSP, we performed cross-linking reactions on a model peptide system, Ac-IR7 (Ac-IEAEKGR, $843.94 \mathrm{~g} \cdot \mathrm{mol}^{-1}$ ) under solution conditions known to generate high yields of the cross-linked adducts. Whilst this is not a biologically relevant system, it is an established model to validate NHSester containing cross-linking strategies and to define the characteristic fragmentations of the resultant adducts [21, 43]. As expected, following the linking reaction, crosslinked peptides, dead-end products and unreacted peptide were observed in the mass spectrum. Intermolecular crosslinked peptides were identified by the expected mass $(\mathrm{m} / \mathrm{z}$ 1860), and MS/MS data were recorded (Figure 1).

The intermolecular cross-links introduced by DSP fragment in an analogous fashion to natural cystine disulfides (Scheme 1), with all four possible product ions observed in this case (Figure 1), the structures of which are described in detail in Scheme 2. The four characteristic product ions, $A^{\prime}-$ $\mathrm{D}^{\prime}$, are easily recognizable in this instance, allowing rapid identification of the intermolecular cross-linked peptides.

For comparison, the positive ion electrospray MS/MS data are shown in Supplementary Figure S2. A 66 Da doublet is observed in this spectrum as a result of fragmentation about the disulfide bond, which has previously been considered for DSP cross-link identification using positive ion MALDI [25]. However, these signals are difficult to observe since they occur in addition to the abundant backbone fragmentations which dominate the spectrum. Consequently, detection of intermolecular cross-link sites is cumbersome, and would be more difficult to achieve by automated on-line $\mathrm{MS}^{3}$ methods, making the positive ion approach more complex to implement and conclusively assign cross-linking sites. In fact, in this previously published approach, sequencing is achieved by performing a second MS experiment following disulfide reduction, which is a shortcoming compared with our negative ion approach.

We were able to sequence the intermolecular cross-linked peptides on the QTOF instrument by performing 'pseudo $\mathrm{MS}^{3}$ experiments' (i.e., MS/MS experiments on fragments created by capillary-skimmer dissociation). Characteristic modifications of the lysine side chains (where the linker had bound) were

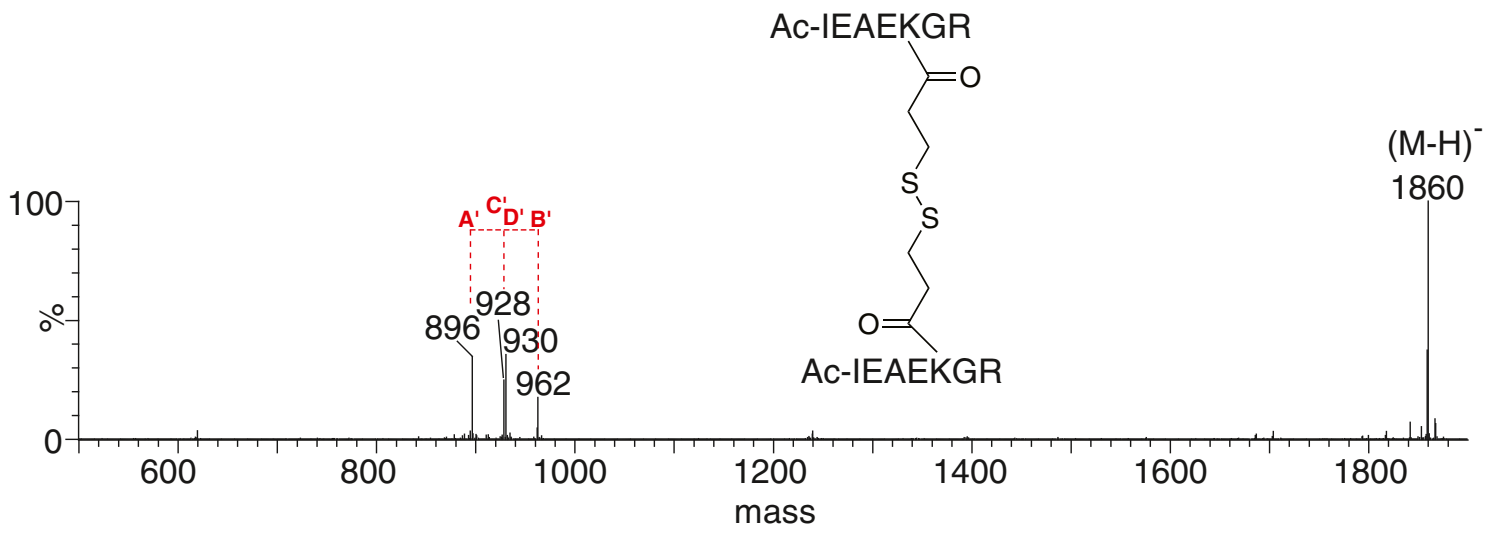

Figure 1. Low energy CID spectrum of DSP cross-linked Ac-IR7 ( $\mathrm{m} / \mathrm{z} 1860)$ gives evidence for the production of four major fragment ions corresponding to cleavage about the disulfide bond (fragments $A^{\prime}-D^{\prime}$ as indicated are described in Scheme 2) 


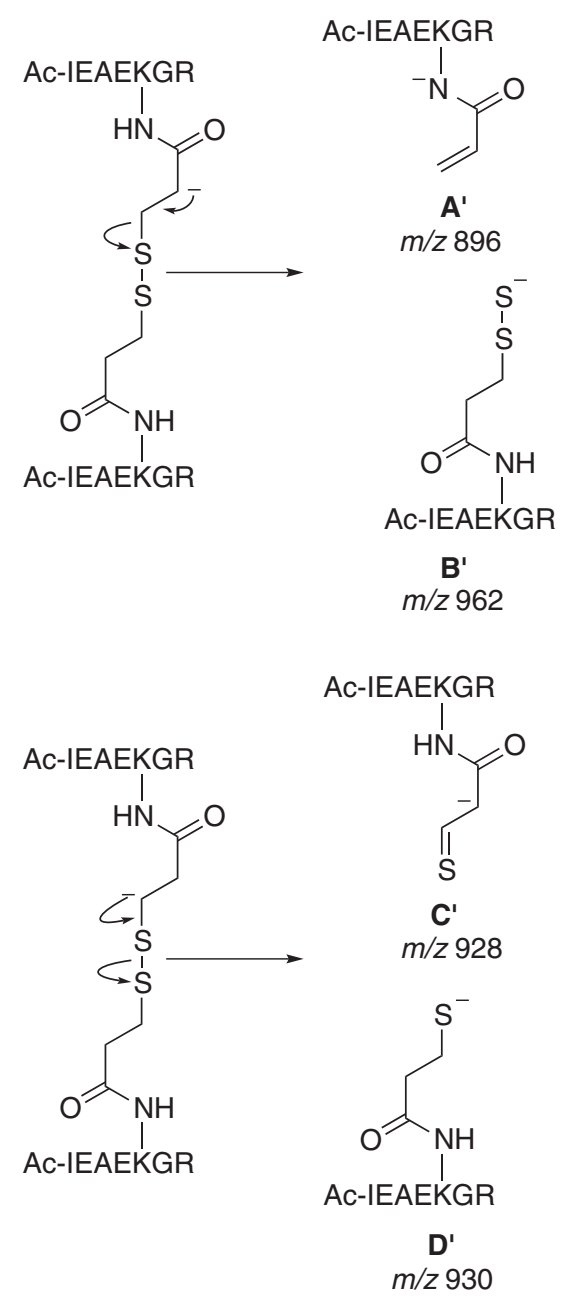

Scheme 2. Structures of Ac-IR7-DSP adducts. Fragment anions $A^{\prime}-D^{\prime}$ correspond to anions $A-D$ in Scheme 1

observed in the spectrum, which would allow for the exact location of cross-linking sites in protein systems of unknown structure. Analysis of the lowest mass DSP adduct $(\mathrm{m} / \mathrm{z}$ 896) (A' in Scheme 2) gave data that allowed easy interpretation and sequencing by the normal backbone cleavages in the negative ion mode (Figure 2). It is also possible to sequence the peptide from the higher mass adducts ( $\mathrm{B}^{\prime}, \mathrm{C}^{\prime}$, and $\mathrm{D}^{\prime}$ in Scheme 2). As an example, the 'pseudo $\mathrm{MS}^{3}$ ' spectrum for the $\mathrm{B}^{\prime}$ adduct is shown in Supplementary Figure S3. In all cases, the spectra are dominated by side chain-induced backbone cleavages from Glu, as is observed in negative ion spectra of similar peptides, together with normal backbone cleavages [35].

These data indicate that our negative ion approach offers a clear advantage over traditional positive ion methodologies for the identification of disulfide containing cross-linked peptides from complex mixtures. The labile disulfide cleaves as expected prior to backbone fragmentation, releasing the individual peptide components which can be sequenced using negative ion $\mathrm{MS}^{3}$. Despite the somewhat reduced sensitivity typically afforded using negative ion MS for analysis of peptides, the detectability of disulfides increases substantially due to their facile, characteristic fragmentations which occur in preference to backbone cleavages, and the cross-linked peptides can be sequenced individually in the same experiment.

\section{Application to Ubiquitin}

From previous work on natural disulfides and our model study above, a summary of the fragmentations expected at low collision energies for the cross-linked adducts is shown in Figure 3. In brief, intermolecular cross-links will fragment like the natural disulfide, with each peptide of the dimer yielding up to four product ions upon CID (as observed for Ac-IR7). Intramolecular cross-links cannot fragment in this manner, as disulfide cleavage will not yield a product ion of changed mass. Instead, characteristic loss of $\mathrm{H}_{2} \mathrm{~S}_{2}$ is expected [32], in addition to side chain-induced backbone cleavages. Dead-end adducts, where one end of the cross-
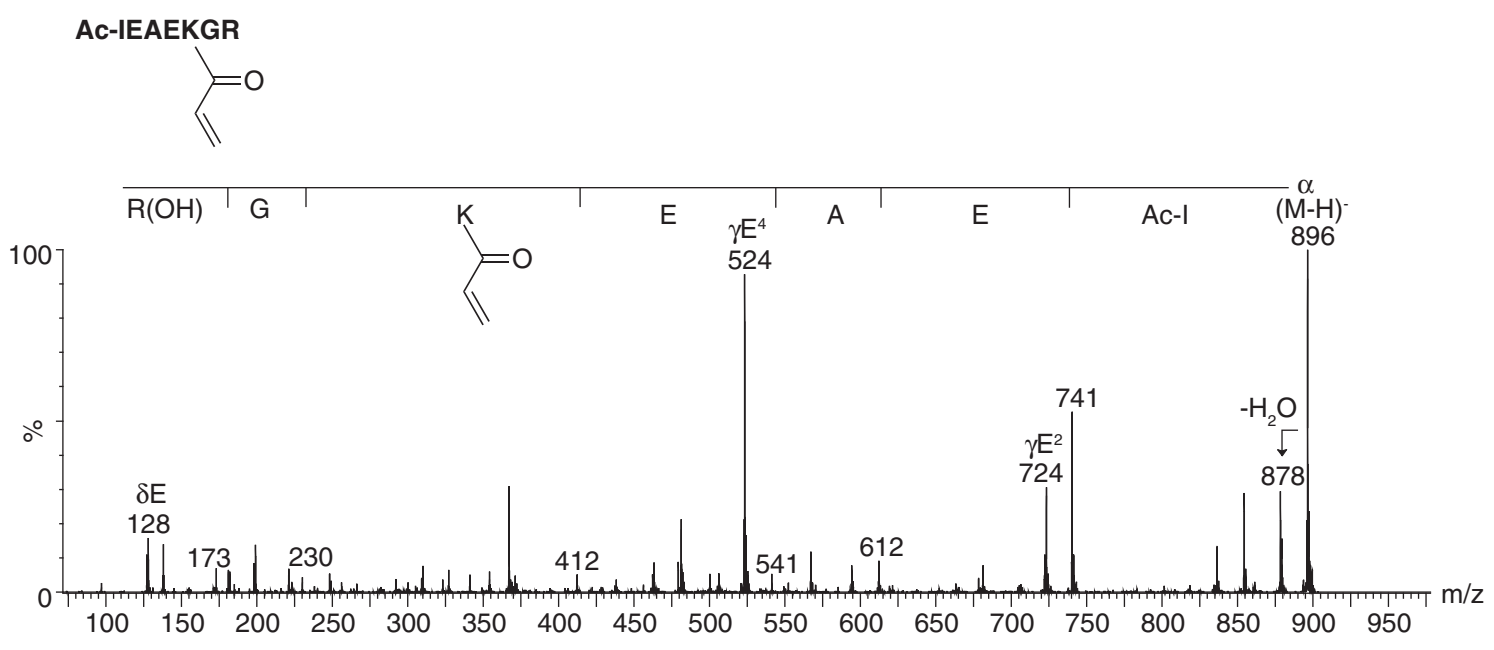

Figure 2. MS/MS spectrum of the $A^{\prime}$ fragment ion formed by capillary-skimmer dissociation $(\mathrm{m} / z$ 896) from DSP cross-linked AcIR7 gives peptide sequence information and cross-link location. Spectrum is magnified as follows; $50-880(\times 3)$. For a description of negative ion cleavages see [35] 


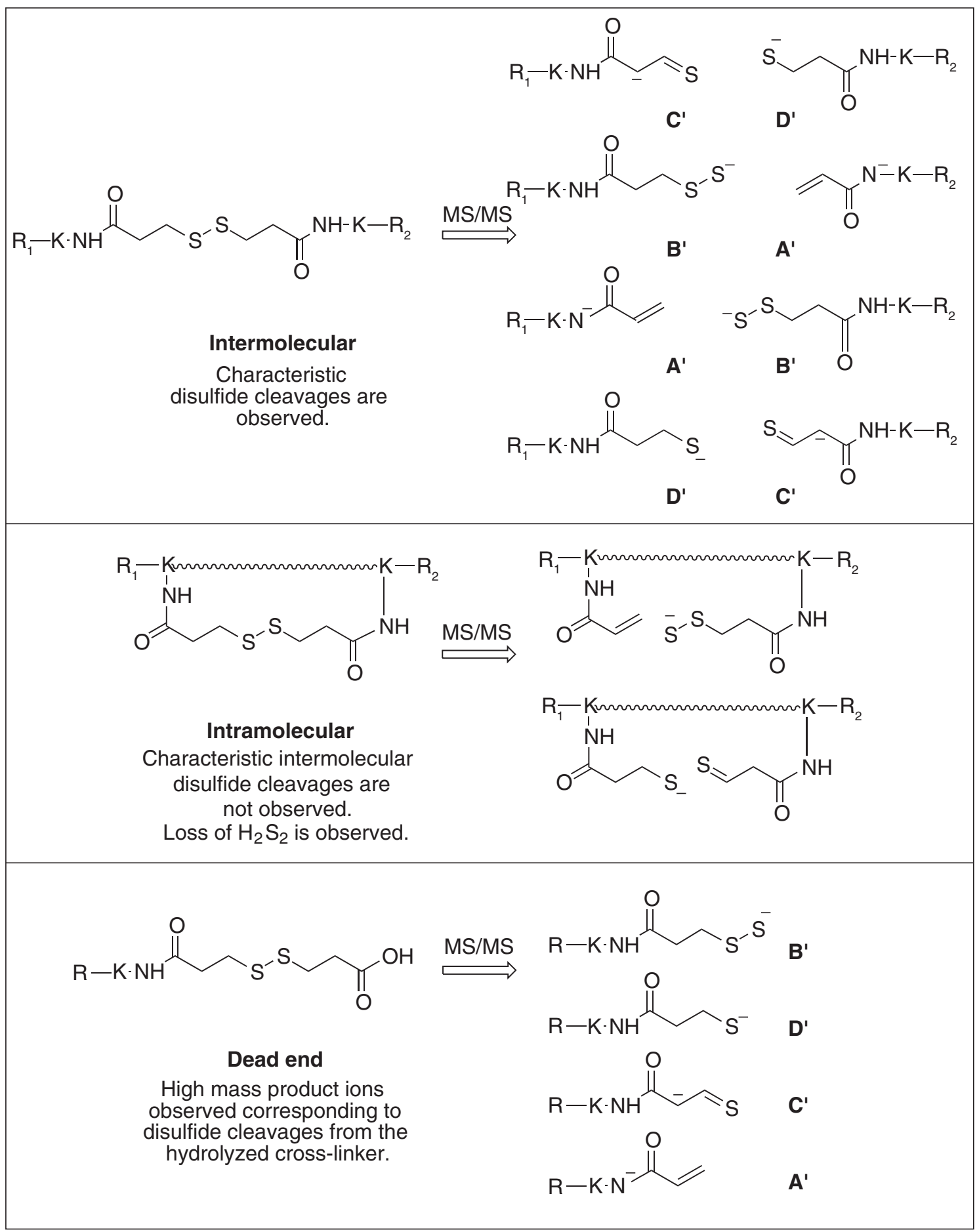

Figure 3. Summary of the expected fragmentations for DSP cross-linked peptides in the negative ion mode. Fragment ions $A^{\prime}-D^{\prime}$ arise from the processes described in Schemes 1 and 2

linker reacts with the protein and the other end is hydrolyzed, will give low mass losses upon collisional activation, corresponding to the facile cleavages of the hydrolyzed disulfide cross-linker.

To further validate our method, we have cross-linked the model protein ubiquitin with DSP. From these data, we have identified intermolecular, intramolecular, and dead-end cross- links, consistent with previous reports [21]. Examples of these characteristic fragmentations are discussed further below.

\section{Intermolecular Cross-Linked Peptides}

MS/MS and 'pseudo $\mathrm{MS}^{3}$ ' data of a symmetrical intermolecular cross-linked species from ubiquitin are shown in Figure 4. Again, 
these cross-linked tryptic peptides fragment analogously to a natural cystine disulfide, showing four fragment ions indicative of a symmetrical intermolecular cross-link (c.f. Schemes 1 and 2 ). In this case, there is an additional, overlapping set of four diagnostic peaks observed in the MS/MS spectrum (denoted A'$\mathrm{H}_{2} \mathrm{O}$ to $\mathrm{D}^{\prime}-\mathrm{H}_{2} \mathrm{O}$ ). This is likely due to the prominent side chain cleavage of Asp [35], which results in the loss of $\mathrm{H}_{2} \mathrm{O}$ (18 Da) from the product ions which contain one Asp residue.

Partial sequence information could be obtained for the peptide fragment corresponding to $\mathrm{m} / \mathrm{z} 1399$ (Figure 4b), conclusively assigning this intermolecular cross-link. Again, side chain-induced backbone cleavages from Asp and Glu residues dominate the spectrum.

An example of a MS/MS spectrum of a nonsymmetrical intermolecular cross-link $(\mathrm{m} / \mathrm{z}$ 3646) is given in Supplementary Figure 4. This again fragmented analogously to a natural cystine disulfide, and produced A'-D' fragments for both peptide halves. Again, side chain-induced loss of water was seen from each of these fragments as a result of the single Asp residue present in each of the peptide halves [35]. The characteristic fragmentation patterns and the mass of the precursor ion enabled the identification of this intermolecular cross-linked product.

\section{Dead-End Cross-Linked Peptides}

A significant advantage of this negative ion approach is that dead-end cross-linking products can be readily identified since they show only small mass losses when subjected to low energy CID (Figure 3), corresponding to loss of the labile, hydrolyzed disulfide cross-linker. An example of this is given in Figure 5, for a dead-end cross-linked peptide from ubiquitin. Products resulting from cleavages of the hydrolyzed linker disulfide bond are observed, as detailed in Figure 3, with a complete description of these ions given in Supplementary Scheme S1. Again, side chain-induced loss of water was seen as a result of the single Asp residue present in each of the peptide chains [35]. Additionally in this case, a fragment corresponding to the side chain-induced $\delta$ backbone cleavage of Asp10 is observed ( $\mathrm{m} / \mathrm{z} 1208)$. This process appears to occur competitively with disulfide cleavage, and consequently cross-linker fragmentation analogous to those from the molecular ion are also noted from this $\delta \mathrm{D}^{10}$ product ion.

\section{Intramolecular Cross-Linked Peptides}

Intramolecular DSP cross-links, such as the example given from ubiquitin in Figure 6, yield much more complex MS/ MS data (summarized in Scheme 3). In this example, the side chain-induced backbone cleavage at both Asp12 and Asp5 occurs to give $m / z$ 1367. Loss of water from this species yields $\mathrm{m} / \mathrm{z}$ 1349. These processes afford what is essentially an intermolecular cross-link, and the disulfide now behaves as such, in the manner outlined in Scheme 3.

(a)
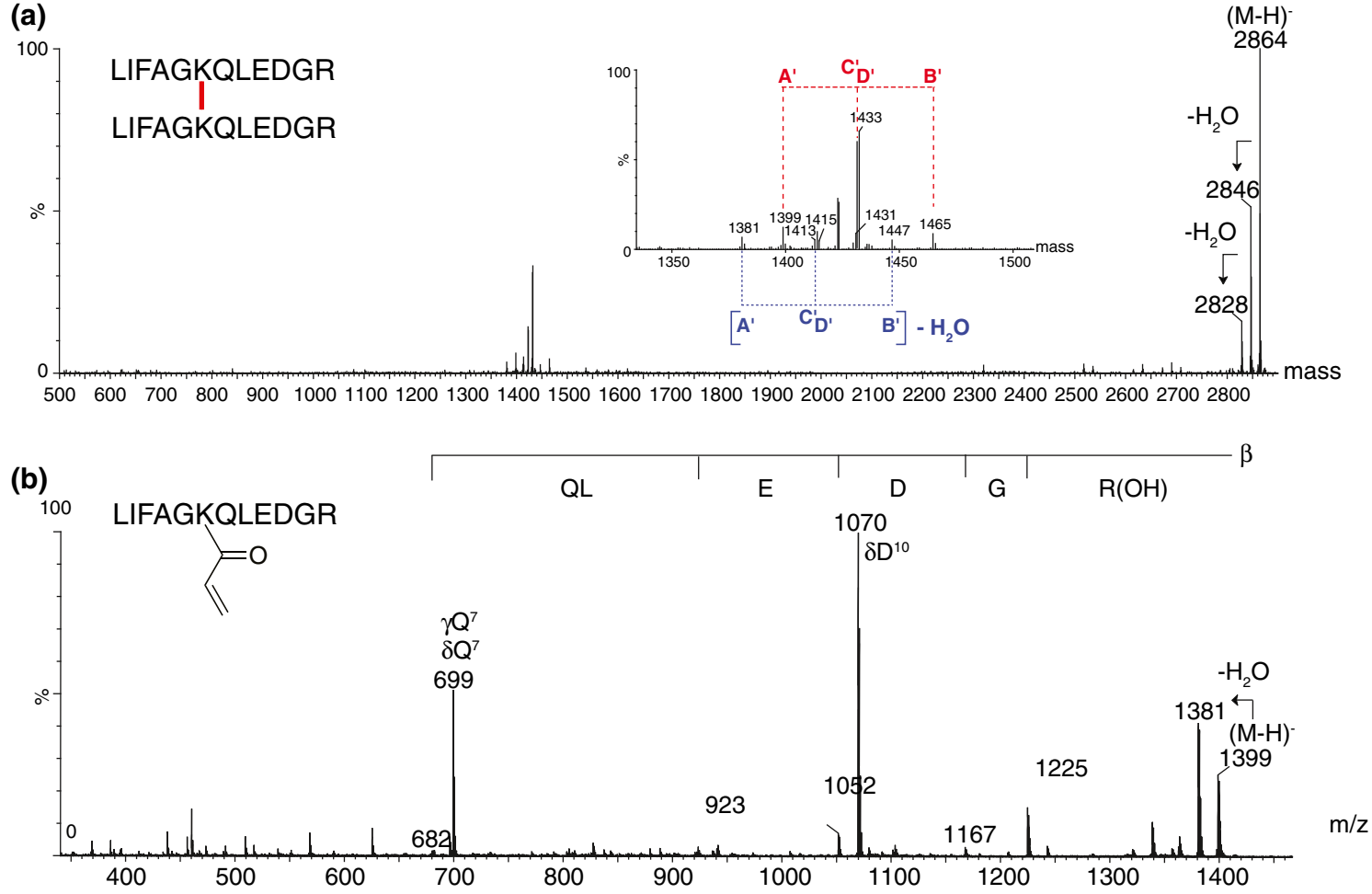

Figure 4. CID data of a symmetrical intermolecular DSP cross-linked peptide from ubiquitin ( $\mathrm{m} / z$ 2864). (a) Low energy CID spectrum gives evidence for production of fragment ions corresponding to cleavage about the disulfide bond (inset shows an enlargement of the relevant region of the spectrum, with the disulfide cleavages indicated by $A^{\prime}-D^{\prime}$, ); (b) MS/MS spectrum of the A' fragment ion formed by capillary-skimmer dissociation $(\mathrm{m} / \mathrm{z} 1399)$ gives partial peptide sequence information and cross-link location 


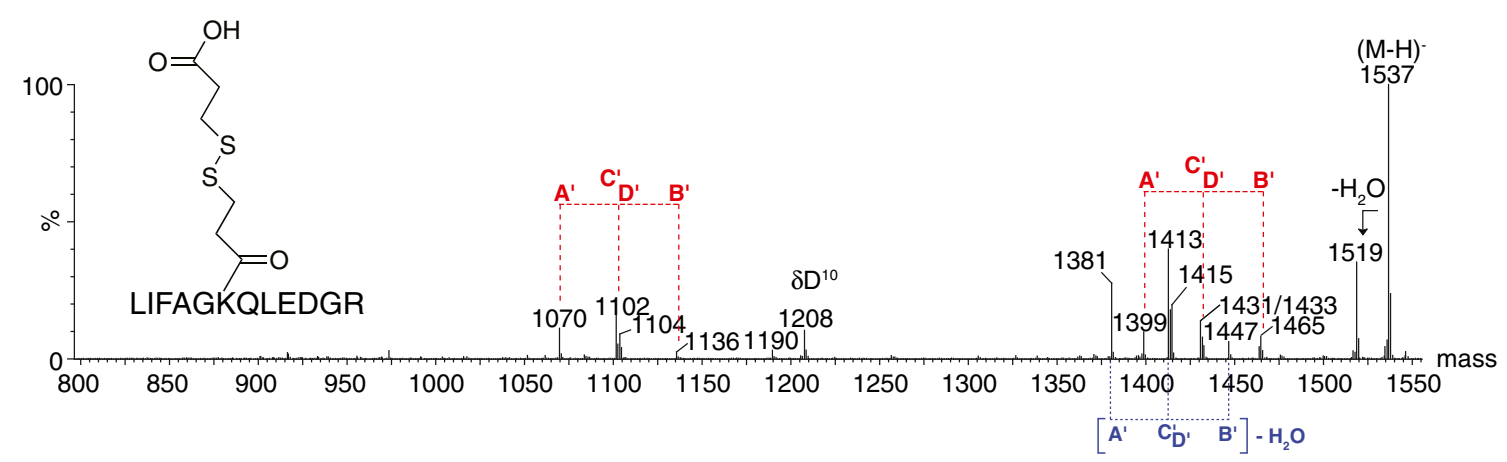

Figure 5. Low energy CID spectrum of a dead-end DSP cross-linked peptide product from ubiquitin $(\mathrm{m} / z$ 1537) shows characteristic fragmentation of the hydrolyzed linker. Fragment ions are labeled $A^{\prime}-D^{\prime}$ corresponding to Figure 3 . An additional set of peaks corresponding to $A^{\prime}-\mathrm{H}_{2} \mathrm{O}$ to $\mathrm{D}^{\prime}-\mathrm{H}_{2} \mathrm{O}$ are also present. Analogous processes occur from the ion $\delta D^{10}$ ion $m / z 1208$ and are labeled accordingly. For a detailed schematic summary of these cleavage processes refer to Supplementary Scheme S1

Not all the possible product ions are observed in the spectrum with the smaller peptide producing only the $\mathrm{C}^{\prime}$ and $\mathrm{D}^{\prime}$ (Schemes 1 and 2) type fragmentations in the spectrum $(\mathrm{m} / z 542$ and 544). In all of the examples we have investigated, this is the only case where fewer than the four possible cleavage products are observed.

This spectrum is complex, yet clearly diagnostic of an intramolecular cross-link, providing significant information about the identity of the peptide involved. The complexity of the intermolecular cross-linked spectra produced in this system is not a disadvantage, since these adducts typically provide limited information on the topology of a protein or protein complex and are often ignored in data analysis. Additionally, this peptide is an unusual example, as it contains an Asp residue between the two cross-linked Lys residues, causing intermolecular disulfide cleavage to be observable following breakage of the peptide backbone at Asp.

\section{Interpretation of Cross-Linking Data}

Here we have presented for the first time a number of examples of the structural analysis of cross-linked peptide products for investigation of higher order protein structure by negative ion MS. Together, these results indicate that disulfide-containing reagents show promise as CID cleavable cross-linking reagents with analysis in the negative ion mode, and that our approach can effectively distinguish dead-end, intra- and inter-cross-linked peptides. In a similar fashion to disulfide containing proteins, the intermolecular cross-linked tryptic peptides undergo facile, characteristic
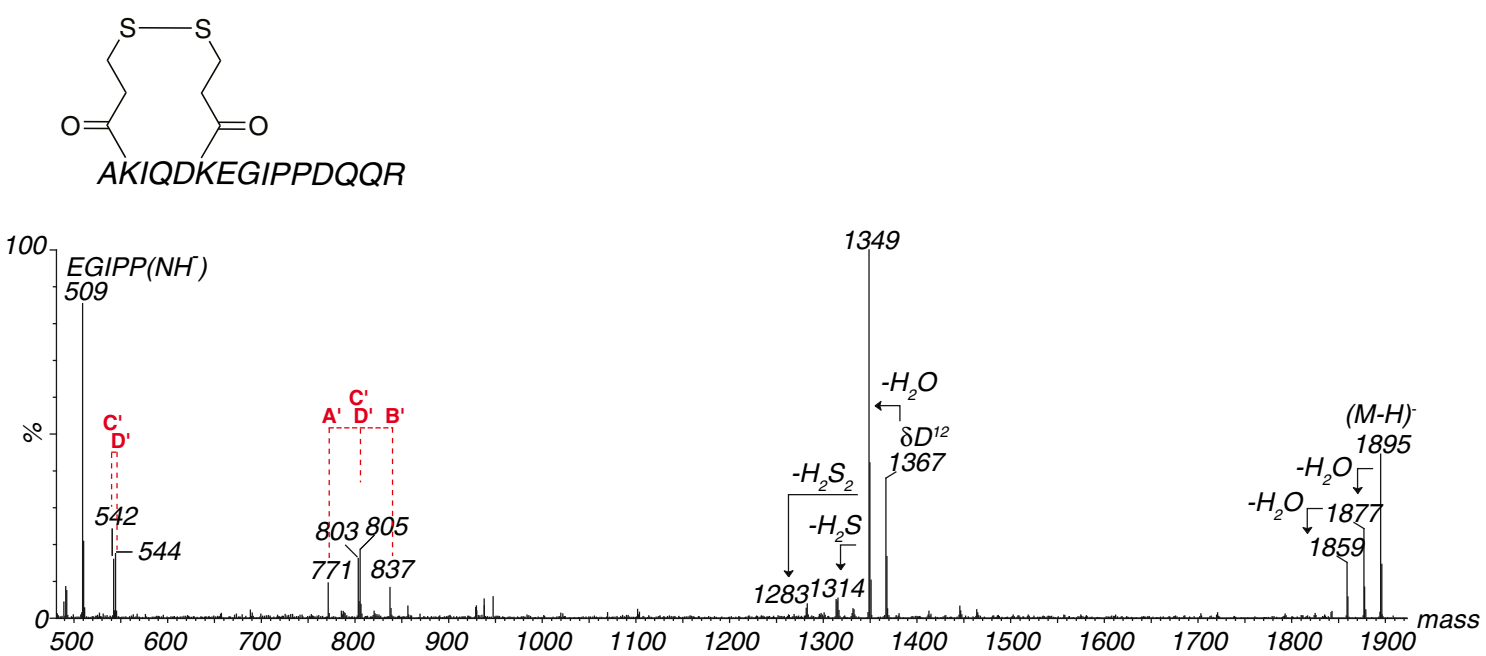

Figure 6. Low energy CID spectrum of an intramolecular DSP cross-linked peptide product from ubiquitin $(\mathrm{m} / z$ 1895) shows complex fragmentation behavior 

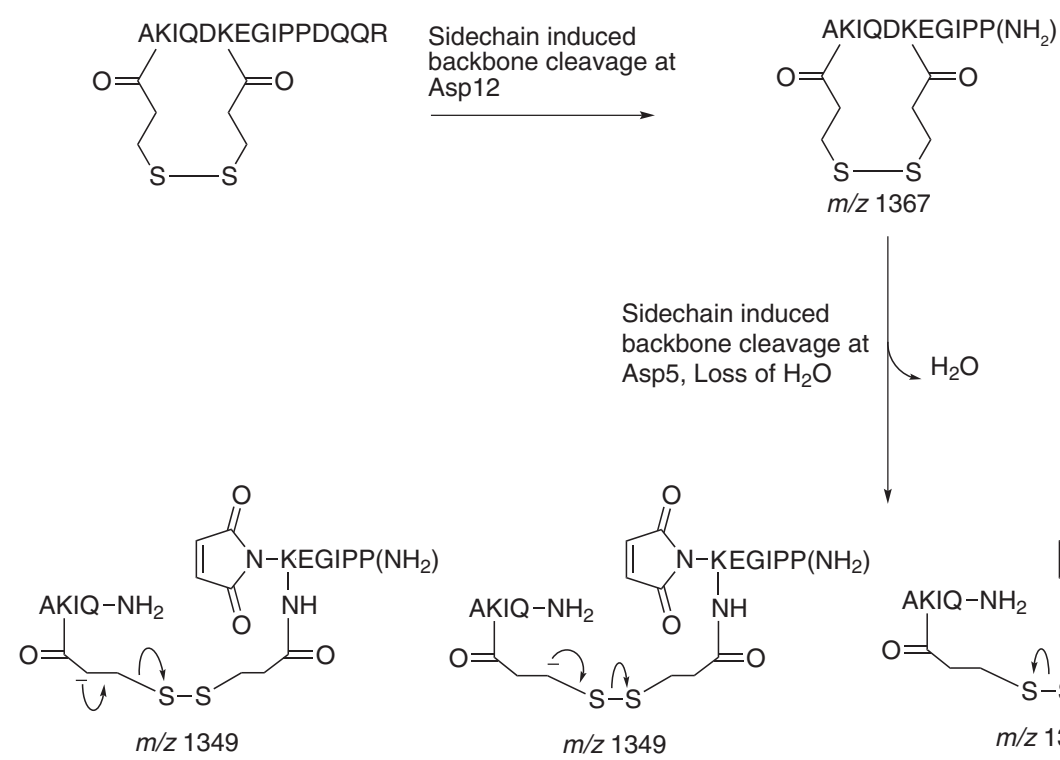

$m / z 1349$
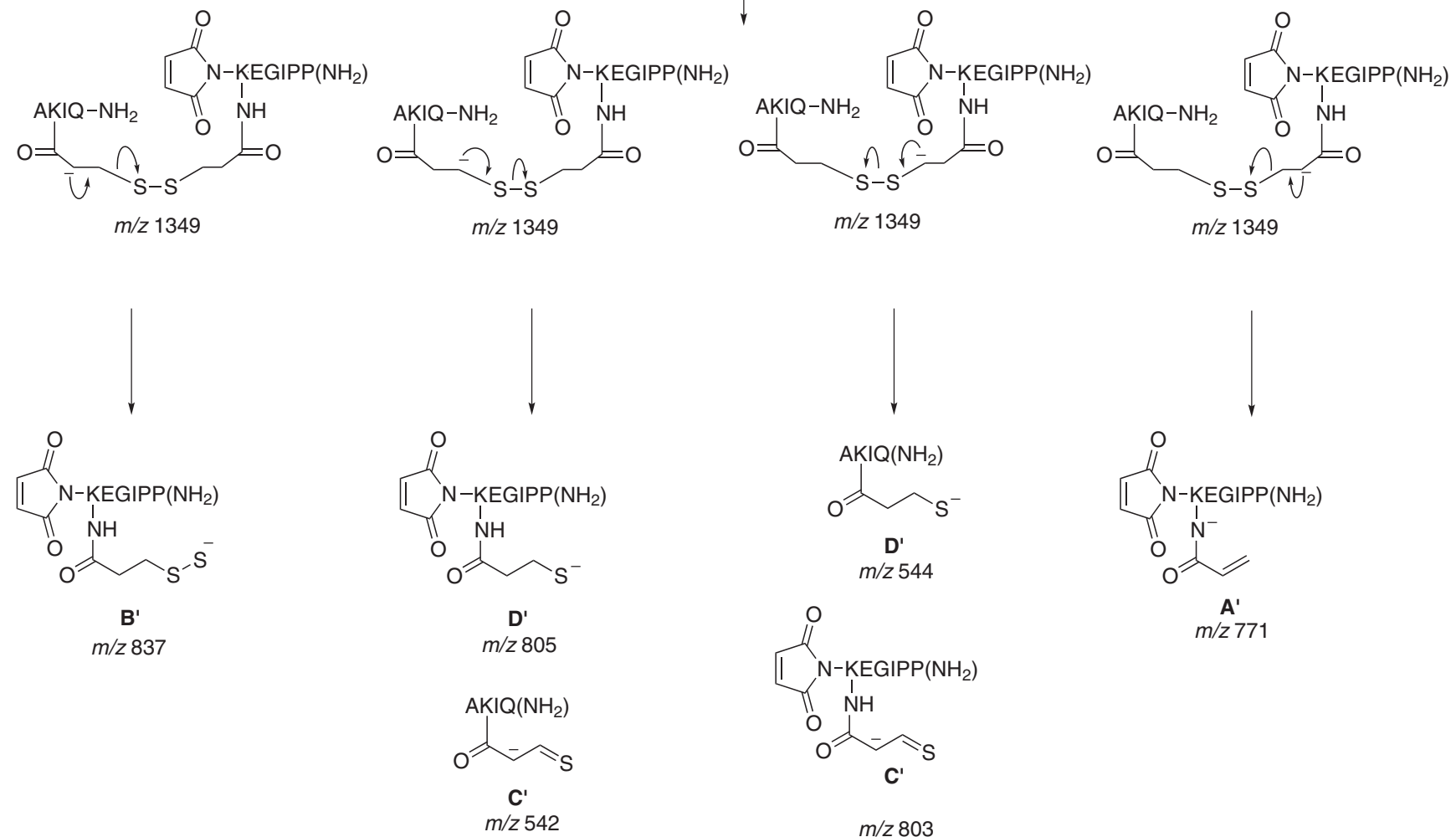

Scheme 3. Structures of fragment ions produced by CID of an intramolecular DSP cross-linked adduct from ubiquitin

fragmentations about the disulfide bond. To identify the modified tryptic peptides, low energy CID can be applied because of the low energy barriers associated with disulfide cleavage, producing fragment ions corresponding to the two peptide halves. All the examples of intermolecular crosslinks that we have investigated produce four product ions upon collisional activation (if symmetrical, eight ions if unsymmetrical, as well as those following Asp induced $\mathrm{H}_{2} \mathrm{O}$ losses). These four peptide fragments $\mathrm{A}^{\prime}-\mathrm{D}^{\prime}$ are diagnostic, easily recognizable (Figure 3, Scheme 2), and are amenable to sequencing by $\mathrm{MS}^{3}$ approaches. Thus, the presence of some or all of these four ions may be used as a marker for the identification of intermolecular cross-links, and can provide the exact site of cross-linking. In addition, competitive side chain-induced fragmentations may also be observed in the spectrum. In many cases, these may be enough to tentatively assign the identity of the peptide.
In comparison, dead-end cross-linked peptides show low mass losses corresponding to cleavage of the hydrolyzed disulfide. These losses again correspond to fragmentation processes producing anions of type $\mathrm{A}^{\prime}-\mathrm{D}^{\prime}$, which can be utilized to easily recognize a dead-end modified peptide (Figure 3, Scheme S1).

Intramolecular cross-linked peptides show much more complex spectra, with side chain-induced backbone cleavages dominating the MS/MS spectrum. However, these spectra show neither low mass losses nor the characteristic disulfide pattern of fragment ions upon CID. This complication is not necessarily disadvantageous as intermolecular cross-links provide little information about the quaternary structures of the complex and are often not investigated. A loss of $\mathrm{H}_{2} \mathrm{~S}_{2}$ is characteristic of an intramolecular disulfide [32].

It should be noted that in a previous study, where the negative ion cleavages of disulfide containing proteins were 
investigated [30], it was shown that all four possible product ions were not evident in all cases. This indicates that some care may need to be taken in analyzing the low energy MS/ MS spectra, as all four possible cleavage products may not be observed. This may have an effect on the development of high throughput data analysis methods using this approach. However, the detection of at least two of the possible fragment anions should provide sufficient diagnostic data to indicate the presence of a cross-linked peptide.

It should also be noted that positive ion MS has been utilized to identify both naturally occurring cystine disulfides and cross-linked products of cysteine-based regents $[25,44-46]$. In these instances, disulfide fragmentations occur simultaneously to the backbone fragmentations used for sequencing [25, 44-46]. Data of this kind makes identification of disulfide-containing peptides time-consuming and difficult. Additionally, it has been reported that disulfide cleavage may be favored from the $[\mathrm{MH}]^{+}$ion but not from those that are multiply charged [29] and, therefore, this positive ion approach has limited applicability. In contrast, our negative ion approach to identify intermolecular or dead-end cross-linked peptides yields MS/MS data which are simpler, containing primarily fragment anions corresponding to the facile cleavages of the disulfide, without the complications of backbone fragmentation. This makes identification and sequencing (by $\mathrm{MS}^{3}$ ) of crosslinked peptides easier than these other positive ion methodologies. Furthermore, negative ion MS has been shown to have other advantages in peptide sequencing, such as the detection of other post-translational modifications [47].

Our future intent is to investigate incorporation of affinity tags such as biotin to enrich disulfide-containing cross-linked peptides from more complicated systems. Furthermore, design of data analysis software to automate detection of characteristic fragment ion series will improve analysis of large data sets such as those from complex protein tryptic digests, and allow for higher throughput utilizing LC-MS. With continued improvement, our development of negative ion amenable disulfide based cross-linking reagents will ultimately assist towards the goal of proteome wide protein structure determination and identification of protein-protein interactions.

\section{Quantum Mechanical Modeling}

Calculations have been performed to determine the energetics of the disulfide fragmentation processes for DSP in a model system, and allow us to propose reasonable structures for the resultant anions. The reaction coordinate profile of the cleavage reaction adjacent to the disulfide calculated at CAM-B3LYP/6$311+\mathrm{G}(\mathrm{d}, \mathrm{p})$ is shown in Supplementary Figure S5. The process to yield a $\mathrm{B}^{\prime}$ ion is kinetically favorable (with a slight barrier of $1 \mathrm{~kJ} \cdot \mathrm{mol}^{-1}$ and $\left.\Delta \mathrm{G}_{\mathrm{r}}(298 \mathrm{~K})=-71 \mathrm{~kJ} \cdot \mathrm{mol}^{-1}\right)$. The IRC calculation shows that following bond cleavage, the anion $\mathrm{R}-\mathrm{S}_{2}{ }^{-}$will move towards the amide hydrogen of the Lys side chain, and form a stable ion-neutral complex by way of a $2.28 \AA$ 'hydrogen bond', suggesting that removal of this hydrogen by $\mathrm{R}-\mathrm{S}_{2}{ }^{-}$yields an $\mathrm{A}^{\prime}$ type ion as depicted in Schemes 1 and 2. In the model system we have shown that deprotonation of the lysine amide nitrogen is a slightly unfavorable process $\left(\Delta \mathrm{G}_{\mathrm{r}}(298 \mathrm{~K})=24 \mathrm{~kJ} \cdot \mathrm{mol}^{-1}\right)$.

The reaction coordinate profile of the cleavage reaction between the sulfur atoms of the disulfide calculated at CAMB3LYP/6-311++G(d,p) is shown in Supplementary Figure S6. The formation of $\mathrm{D}^{\prime}$ is unfavorable by $22 \mathrm{~kJ} \cdot \mathrm{mol}^{-1}$. Again, ionneutral complex formation drives charge transfer by deprotonation at the enolate position to yield $\mathrm{C}^{\prime}$ in a kinetically favorable fashion (with a slight barrier of $16 \mathrm{~kJ} \cdot \mathrm{mol}^{-1}$ and $\left.\Delta \mathrm{G}_{\mathrm{r}}(298 \mathrm{~K})=-14 \mathrm{~kJ} \cdot \mathrm{mol}^{-1}\right)$.

These disulfide cleavage processes are more energetically favorable than the negative ion backbone cleavage processes [35] and therefore occur at lower collision energies. These are the most energetically favorable of the negative ion cleavages that we have studied to date.

\section{Conclusions}

For the first time, negative ion MS has been used to identify and provide information about cross-linked peptides and proteins. We have shown that the negative ion cleavages of adducts containing disulfide cross-linking reagents can be useful in identifying intermolecular, intramolecular, and dead-end cross-linked peptides amongst complex mixtures and can readily localize the cross-linking site with residue level resolution. The spectra obtained are diagnostic for the cross-link type, allow for sequencing and identification of the cross-linked species, and are suitable for investigation of proteins and protein assemblies of unknown structure.

Negative ion MS provides a clear advantage over conventional positive ion MS for the identification of these disulfide containing cross-links due to their facile, characteristic fragmentation behavior. These are the most facile negative ion cleavages to have been studied to date. The resultant MS/MS data of intermolecular cross-linked peptides contain only these disulfide cleavage products, which are diagnostic, easy to recognize, and easy to sequence by $\mathrm{MS}^{3}$.

Now that the characteristic fragmentations of the modified peptides is understood, it is our intention to use this negative ion approach to develop methods for high-throughput analysis of unknown protein complex structures, so that identification and sequencing can occur simultaneously.

\section{Acknowledgments}

The authors acknowledge support for this work by Australian Research Council Discovery Project Funding (DP 1093143). A.N.C. acknowledges the support of an Australian Postgraduate Award for Ph.D. funding.

\section{References}

1. Sinz, A.: Investigation of protein-protein interactions in living cells by chemical crosslinking and mass spectrometry. Anal. Bioanal. Chem. 397, 3433-3440 (2010) 
2. Sinz, A.: Chemical cross-linking and mass spectrometry to map threedimensional protein structures and protein-protein interactions. Mass Spectrom. Rev. 25, 663-682 (2006)

3. Leitner, A., Walzthoeni, T., Kahraman, A., Herzog, F., Rinner, O., Beck, M., Aebersold, R.: Probing native protein structures by chemical cross-linking, mass spectrometry, and bioinformatics. Mol. Cell. Proteom. 9, 1634-1649 (2010)

4. Rappsilber, J.: The beginning of a beautiful friendship: cross-linking/ mass spectrometry and modeling of proteins and multi-protein complexes. J. Struct. Biol. 173, 530-540 (2011)

5. Petrotchenko, E.V., Borchers, C.H.: Crosslinking combined with mass spectrometry for structural proteomics. Mass Spectrom. Rev. 29, 862 876 (2010)

6. Maiolica, A., Cittaro, D., Borsotti, D., Sennels, L., Ciferri, C., Tarricone, C., Musacchio, A., Rappsilber, J.: Structural analysis of multiprotein complexes by cross-linking, mass spectrometry, and database searching. Mol. Cell. Proteom. 6, 2200-2211 (2007)

7. Sinz, A., Kalkhof, S., Ihling, C.: Mapping protein interfaces by a trifunctional cross-linker combined with MALDI-TOF and ESI-FTICR mass spectrometry. J. Am. Soc. Mass Spectrom. 16, 1921-1931 (2005)

8. Hurst, G.B., Lankford, T.K., Kennel, S.J.: Mass spectrometric detection of affinity purified crosslinked peptides. J. Am. Soc. Mass Spectrom. 15, 832-839 (2004)

9. Nessen, M.A., Kramer, G., Back, J., Baskin, J.M., Smeenk, L.E., de Koning, L.J., van Maarseveen, J.H., de Jong, L., Bertozzi, C.R., Hiemstra, H., de Koster, C.G.: Selective enrichment of azide-containing peptides from complex mixtures. J. Proteome Res. 8, 3702-3711 (2009)

10. Kasper, P.T., Back, J.W., Vitale, M., Hartog, A.F., Roseboom, W., de Koning, L.J., van Maarseveen, J.H., Muijsers, A.O., de Koster, C.G., de Jong, L.: An aptly positioned azido group in the spacer of a protein cross-linker for facile mapping of lysines in close proximity. ChemBioChem 8, 1281-1292 (2007)

11. Chowdhury, S.M., Du, X., Tolic, N., Wu, S., Moore, R.J., Mayer, M.U., Smith, R.D., Adkins, J.N.: Identification of cross-linked peptides after click-based enrichment using sequential collision-induced dissociation and electron transfer dissociation tandem mass spectrometry. Anal. Chem. 81, 5524-5532 (2009)

12. Tang, X., Munske, G.R., Siems, W.F., Bruce, J.E.: Mass spectrometry identifiable cross-linking strategy for studying protein-protein interactions. Anal. Chem. 77, 311-318 (2005)

13. Trester-Zedlitz, M., Kamada, K., Burley, S.K., Fenyo, D., Chait, B.T., Muir, T.W.: A modular cross-linking approach for exploring protein interactions. J. Am. Chem. Soc. 125, 2416-2425 (2003)

14. Chu, F., Mahrus, S., Craik, C.S., Burlingame, A.L.: Isotope-coded and affinity-tagged cross-linking (ICATXL): an efficient strategy to probe protein interaction surfaces. J. Am. Chem. Soc. 128, 10362-10363 (2006)

15. Taverner, T., Hall, N.E., O'Hair, R.A., Simpson, R.J.: Characterization of an antagonist interleukin-6 dimer by stable isotope labeling, crosslinking, and mass spectrometry. J. Biol. Chem. 277, 46487-46492 (2002)

16. Petrotchenko, E.V., Olkhovik, V.K., Borchers, C.H.: Isotopically coded cleavable cross-linker for studying protein-protein interaction and protein complexes. Mol. Cell. Proteom. 4, 1167-1179 (2005)

17. Back, J.W., Notenboom, V., de Koning, L.J., Muijsers, A.O., Sixma, T.K., de Koster, C.G., de Jong, L.: Identification of cross-linked peptides for protein interaction studies using mass spectrometry and ${ }^{18} \mathrm{O}$ labeling. Anal. Chem. 74, 4417-4422 (2002)

18. Schulz, D.M., Kalkhof, S., Schmidt, A., Ihling, C., Stingl, C., Mechtler, K., Zschornig, O., Sinz, A.: Annexin A2/P11 interaction: new insights into annexin A2 tetramer structure by chemical crosslinking, highresolution mass spectrometry, and computational modeling. Proteins 69, 254-269 (2007)

19. Ihling, C., Schmidt, A., Kalkhof, S., Schulz, D.M., Stingl, C., Mechtler, K., Haack, M., Beck-Sickinger, A.G., Cooper, D.M., Sinz, A.: Isotopelabeled cross-linkers and Fourier transform ion cyclotron resonance mass spectrometry for structural analysis of a protein/peptide complex. J. Am. Soc. Mass Spectrom. 17, 1100-1113 (2006)

20. Muller, M.Q., Dreiocker, F., Ihling, C.H., Schafer, M., Sinz, A. Cleavable cross-linker for protein structure analysis: reliable identification of cross-linking products by tandem MS. Anal. Chem. 82, 6958$6968(2010)$

21. Kao, A., Chiu, C.L., Vellucci, D., Yang, Y., Patel, V.R., Guan, S., Randall, A., Baldi, P., Rychnovsky, S.D., Huang, L.: Development of a novel cross-linking strategy for fast and accurate identification of crosslinked peptides of protein complexes. Mol. Cell Proteom 10, M110 002212 (2011)

22. Back, J.W., Hartog, A.F., Dekker, H.L., Muijsers, A.O., de Koning, L.J., de Jong, L.: A new crosslinker for mass spectrometric analysis of the quaternary structure of protein complexes. J. Am. Soc. Mass Spectrom. 12, 222-227 (2001)

23. Soderblom, E.J., Goshe, M.B.: Collision-induced dissociative chemical cross-linking reagents and methodology: applications to protein structural characterization using tandem mass spectrometry analysis. Anal. Chem. 78, 8059-8068 (2006)

24. Soderblom, E.J., Bobay, B.G., Cavanagh, J., Goshe, M.B.: Tandem mass spectrometry acquisition approaches to enhance identification of protein-protein interactions using low-energy collision-induced dissociative chemical crosslinking reagents. Rapid Commun. Mass Spectrom. 21, 3395-3408 (2007)

25. King, G.J., Jones, A., Kobe, B., Huber, T., Mouradov, D., Hume, D.A., Ross, I.L.: Identification of disulfide-containing chemical cross-links in proteins using MALDI-TOF/TOF-mass spectrometry. Anal. Chem. 80, 5036-5043 (2008)

26. Lu, Y., Tanasova, M., Borhan, B., Reid, G.E.: Ionic reagent for controlling the gas-phase fragmentation reactions of cross-linked peptides. Anal. Chem. 80, 9279-9287 (2008)

27. Gardner, M.W., Vasicek, L.A., Shabbir, S., Anslyn, E.V., Brodbelt, J.S.: Chromogenic cross-linker for the characterization of protein structure by infrared multiphoton dissociation mass spectrometry. Anal. Chem. 80, 4807-4819 (2008)

28. Zhang, H., Tang, X., Munske, G.R., Tolic, N., Anderson, G.A., Bruce, J.E.: Identification of protein-protein interactions and topologies in living cells with chemical cross-linking and mass spectrometry. Mol. Cell. Proteom. 8, 409-420 (2009)

29. Wells, J.M., Stephenson, J.L., McLuckey, S.A.: Charge dependence of protonated insulin decompositions. Int. J. Mass Spectrom. 203, A1-A9 (2000)

30. Andreazza, H.J., Bowie, J.H.: The application of negative ion electrospray mass spectrometry for the sequencing of underivatized disulfidecontaining proteins: insulin and lysozyme. Phys. Chem. Chem. Phys. 12, 13400-13407 (2010)

31. Bilusich, D., Bowie, J.H.: Fragmentations of $(\mathrm{M}-\mathrm{H})^{-}$anions of underivatised peptides. Part 2. Characteristic cleavages of Ser and Cys and of disulfides and other post-translational modifications, together with some unusual internal processes. Mass Spectrom Rev 28, 20-34 (2009)

32. Bilusich, D., Maselli, V.M., Brinkworth, C.S., Samguina, T., Lebedev, A.T., Bowie, J.H.: Direct identification of intramolecular disulfide links in peptides using negative ion electrospray mass spectra of underivatised peptides. A joint experimental and theoretical study. Rapid Commun. Mass Spectrom 19, 3063-3074 (2005)

33. Bilusich, D., Bowie, J.H.: Identification of intermolecular disulfide linkages in underivatised peptides using negative ion electrospray mass spectrometry. A joint experimental and theoretical study. Rapid Commun. Mass Spectrom. 21, 619-628 (2007)

34. Zhang, M., Kaltashov, I.A.: Mapping of protein disulfide bonds using negative ion fragmentation with a broadband precursor selection. Anal. Chem. 78, 4820-4829 (2006)

35. Bowie, J.H., Brinkworth, C.S., Dua, S.: Collision-induced fragmentations of the $(\mathrm{M}-\mathrm{H})^{-}$parent anions of underivatized peptides: an aid to structure determination and some unusual negative ion cleavages. Mass Spectrom. Rev. 21, 87-107 (2002)

36. Becke, A.D.: Density-functional thermochemistry. III. The role of exact exchange. J. Chem. Phys. 98, 5648-5652 (1993)

37. Yanai, T., Tew, D.P., Handy, N.C.: A new hybrid exchange-correlation functional using the Coulomb-attenuating method (CAM-B3LYP). Chem. Phys. Lett. 393, 51-57 (2004)

38. Stephens, P.J., Devlin, F.J., Chabalowski, C.F., Frisch, M.J.: Ab-Initio calculation of vibrational absorption and circular-dichroism spectra using density-functional force-fields. J. Phys. Chem. 98, 11623-11627 (1994)

39. Frisch, M.J., Trucks, G.W., Schlegel, H.B., Scuseria, G.E., Robb, M.A., Cheeseman, J.R., Scalmani, G., Barone, V., Mennucci, B., Petersson, G.A., Nakatsuji, H., Caricato, M., Li, X., Hratchian, H.P., Izmaylov, A.F., Bloino, J., Zheng, G., Sonnenberg, J.L., Hada, M., Ehara, M., Toyota, K., Fukuda, R., Hasegawa, J., Ishida, M., Nakajima, T., Honda, Y., Kitao, O., Nakai, H., Vreven, T., Montgomery Jr., J.A., Peralta, J.E., Ogliaro, F., Bearpark, M., Heyd, J.J., Brothers, E., Kudin, K.N., Staroverov, V.N., Kobayashi, R., Normand, J., Raghavachari, K., 
Rendell, A., Burant, J.C., Iyengar, S.S., Tomasi, J., Cossi, M., Rega, N., Millam, J.M., Klene, M., Knox, J.E., Cross, J.B., Bakken, V., Adamo, C., Jaramillo, J., Gomperts, R., Stratmann, R.E., Yazyev, O., Austin, A.J., Cammi, R., Pomelli, C., Ochterski, J.W., Martin, R.L., Morokuma, K., Zakrzewski, V.G., Voth, G.A., Salvador, P., Dannenberg, J.J., Dapprich, S., Daniels, A.D., Farkas, Ö., Foresman, J.B., Ortiz, J.V., Cioslowski, J., Fox, D.J.: Gaussian 09, Revision B.01. Gaussian, Inc, Wallingford (2009)

40. Fukui, K.: The path of chemical-reactions - the IRC approach. Acc. Chem. Res. 14, 363-368 (1981)

41. Gonzalez, C., Schlegel, H.B.: An improved algorithm for reaction-path following. J. Chem. Phys. 90, 2154-2161 (1989)

42. Gonzalez, C., Schlegel, H.B.: Reaction-path following in massweighted internal coordinates. J. Phys. Chem. 94, 5523-5527 (1990)

43. Vellucci, D., Kao, A., Kaake, R.M., Rychnovsky, S.D., Huang, L.: Selective enrichment and identification of azide-tagged cross-linked peptides using chemical ligation and mass spectrometry. J. Am. Soc. Mass Spectrom. 21, 1432-1445 (2010)

44. Schnaible, V., Wefing, S., Resemann, A., Suckau, D., Bucker, A., Wolf-Kummeth, S., Hoffman, D.: Screening for disulfide bonds in proteins by MALDI in-source decay and LIFT-TOF/TOF-MS. Anal. Chem. 74, 4980-4988 (2002)

45. Jones, M.D., Patterson, S.D., Lu, H.S.: Determination of disulfide bonds in highly bridged disulfide-linked peptides by matrix-assisted laser desorption/ionization mass spectrometry with postsource decay. Anal. Chem. 70, 136-143 (1998)

46. Gaucher, S.P., Hadi, M.Z., Young, M.M.: Influence of crosslinker identity and position on gas-phase dissociation of Lys-Lys crosslinked peptides. J. Am. Soc. Mass Spectrom. 17, 395-405 (2006)

47. Palumbo, A.M., Smith, S.A., Kalcic, C.L., Dantus, M., Stemmer, P.M., Reid, G.E.: Tandem mass spectrometry strategies for phosphoproteome analysis. Mass Spectrom. Rev. 30, 600-625 (2011) 